\title{
Commentary to: Close relationship between the short round ligament and the ovarian prolapsed inguinal hernia in female infants-H Kuyama, S Uemura, A Yoshida, M Yamamoto, PSI (2019) 35:625-629
}

\author{
John M. Hutson ${ }^{1}$ (1) \\ Published online: 6 August 2019 \\ ๑) Springer-Verlag GmbH Germany, part of Springer Nature 2019
}

I have read with interest this paper [1] describing a link between the round ligament length and inguinal hernia in female infants. The authors found that the intra-abdominal length of the round ligament was shortest on the side of a clinical hernia, especially in infants less than 1 year of age. The authors conclude that the short round ligament results in prolapse of the ovary into the hernial sac.

The study is well done but the authors were unable to measure the full length of the round ligament, which normally ends just outside the external inguinal ring in female infants with no hernia (Attah A, Hutson JM. The anatomy of the female gubernaculum is different from the male. ANZ J Surg 61:380-4, 1991).

Initially, the gubernaculum forms before sexual differentiation and is called the genitoinguinal ligament. Prior to the 1990s, anatomy books stated that the female gubernaculum, or round ligament, ended in the labium majora, analogous to the male gubernaculum ending inside the scrotum. Once it was appreciated that before the inguinoscrotal phase of testicular descent, the gubernaculum ended just outside the future external inguinal ring, and the subsequent migration from the inguinal canal to the scrotum required testosterone, we thought that the round ligament should not extend to the labium majora, as there were no androgens in the female.

We were able to confirm this by studying the attachment of the round ligament in infants undergoing postmortem

This comment refers to the article available at https://doi. org/10.1007/s00383-019-04465-6.

An author's reply to this comment is available at https://doi. org/10.1007/s00383-019-04529-7.

John M. Hutson

john.hutson@rch.org.au

1 Royal Children's Hospital, Parkville, Australia after sudden infant death syndrome (SIDS). The authors describe that the intra-abdominal part of the round ligament is longer in older infants, which is consistent with the known elongation of the ligament with age.

The paper concludes that the prolapse of the ovary into an inguinal hernia may result from the short round ligament, but we would like to suggest an alternative explanation. As the female gubernaculum ends just outside the external inguinal ring, and that the processus vaginalis is a peritoneal diverticulum forming within the gubernaculum, development of an inguinal hernia in a girl will lead to stretching of the female processus vaginalis beyond the external ring. This mechanical stretching will also potentially displace the end of the round ligament on the side of the hernia sac, which may pull the intra-abdominal part of the sac, thereby shortening its length. Thus, ovarian prolapse and round ligament shortening may both be consequences of the peritoneum sliding into the sac as the hernia enlarges, rather than one causing the other.

\section{Reference}

1. Kuyama H, Uemura S, Yoshida A et al (2019) Pediatr Surg Int 35:625. https://doi.org/10.1007/s00383-019-04465-6

Publisher's Note Springer Nature remains neutral with regard to jurisdictional claims in published maps and institutional affiliations. 